\begin{tabular}{l|l}
\hline SISTEMA \\
ELETRONICO \\
DE REVISTAS \\
SER I UfPR
\end{tabular}

\title{
Bem Viver como paradigma de desenvolvimento: utopia ou alternativa possível?
}

\section{Good Living as a Paradigm of Development: Utopia or Alternative Possible?}

\author{
Liliane Cristine Schlemer ALCANTARA ${ }^{1 *}$, Carlos Alberto Cioce SAMPAIO ${ }^{2,3}$ \\ ${ }^{1}$ Programa de Pós-Graduação em Agroecologia e Desenvolvimento Rural da Universidade Federal de São Carlos (UFSCar), Araras, SP, Brasil. \\ ${ }^{2}$ Programas de Pós-Graduação em Desenvolvimento Regional, Fundação Universidade Regional de Blumenau (FURB), Blumenau, SC, Brasil. \\ ${ }^{3}$ Programa de Pós-Graduação em Gestão Ambiental, Universidade Positivo, Curitiba, PR, Brasil. \\ *E-mail de contato: lilianecsa@yahoo.com.br
}

Artigo recebido em 21 de setembro de 2016, versão final aceita em 7 de fevereiro de 2017.

RESUMO: A sociedade de consumo coloca em risco a sobrevivência do planeta. Na América Latina, surgem abordagens de desenvolvimento, ancoradas em paradigmas e ideologias com larga existência, como o "Bem Viver". No esforço de identificar o que já foi publicado sobre "Bem Viver", "Bien Vivir/Vivir Bien" e "Good Living", analisou-se, de 2001 a 2015, 66 periódicos qualificados de forma articulada, por meio de estudo bibliométrico, utilizando-se como técnica de medição a lei de dispersão de periódicos de Bradford. A pesquisa enquadra-se como bibliográfica e documental. Os artigos continham, além da palavra "Bem Viver", no título, resumo, palavras-chave e/ou na introdução, termos associados ao tema principal, a exemplo de: "desenvolvimento," "bem comum", "bem estar subjetivo", "interculturalidade" e "transdisciplinaridade". As fontes bibliográficas de pesquisa foram as plataformas Web of Science, Scielo e Portal de Periódicos da CAPES. O resultado demonstrou que o Bem Viver, enquanto proposta em construção, apresenta-se como uma crítica ao consumo inconsequente quanto à degradação ambiental e, enquanto sinônimo de felicidade, busca privilegiar o equilíbrio entre bem-estar e sustentabilidade.

Palavras-chave: Bem Viver; desenvolvimento; interculturalidade; transdisciplinaridade.

ABSTRACT: The consumer society endangers the survival of the planet. In Latin America alternative approaches of development arise, anchored to paradigms and ideologies which has a wide existence, such as the "Good Living" concept. In an effort to identify what has been published about "Viver Bem", "Vivir Bien / Vivir Bien" and "Good Living", have been analyzed between 2001 and 2015, by 66 very qualified periodic, in an articulated way, through bibliometric study, whose has used, such as a measuring technique, the "Bradford" periodic dispersion law. The research fits, as much as, into a bibliographic or into a documental way. The results showed up that the articles contained besides the phrase "Good Living" in the title, abstract, keywords and/or introduction, terms related to the main theme such as "development," "common good", "subjective well-being", "interculturalism" 
and "transdisciplinarity". Bibliographical research sources were gathering into the Web of Science platform, Scielo, and CAPES Journal Portal. The results showed up that Good Living is, as such as a proposal under construction, the one which would presents itself such as a criticism of the inconsequential consumption for the environmental degradation; while synonymous of happiness, aims to privilege the balance between well being and sustainability.

Keywords: Good Living; development; interculturalism; transdisciplinarity.

\section{Introdução}

Os limites do desenvolvimento não são absolutos, mas condicionados pelo estágio da tecnologia, organização da sociedade, intervenção sobre o ambiente e pela capacidade da biosfera em absorver os impactos das atividades do homem. Nesse sentido, faz-se necessário superar a visão clássica do desenvolvimento como sinônimo de crescimento econômico perpétuo, progresso linear e antropocentrismo desmedido (Gudynas, 2011).

As últimas edições do Fórum Social Mundial sugerem discutir alternativas de um novo modelo civilizatório que tenha como base o Bem Viver, na tentativa de reconsiderar as relações com a natureza e que condena o consumo não responsável (Coraggio \& Laville, 2014). Indicadores, como Índice de Necessidades Básicas (In)Satisfeitas, Índices de Vulnerabilidade, Índice do Desenvolvimento Humano e outros, possuem limitação para se aferir o Bem Viver, o que se questiona se é próprio de seu significado sua dimensão subjetiva e, por assim ser, a ciência, de base racional, ainda tem dificuldade de compreender o tema. Daí a necessidade de se incorporar a visão transdisciplinar para melhor compreender tal fenômeno.

Conforme Walsh (2005), a distribuição e classificação da população em ranques, lugares e papéis sociais resultam da configuração do capitalismo, da cultura e da produção do conhecimento sob a hegemonia ocidental, caracterizada como eurocentrismo. Segundo Quijano (2000, p. 549-550), resultante de
"[...] uma racionalidade ou perspectiva de conhecimento que se fez globalmente hegemônico, colonializando e dominando outras formações conceituais e seus conhecimentos concretos respectivos."

Para Sassen (2008, p. 1), o que a sociedade denomina de "economia global", sob a lógica de uma economia sem fronteiras, com hierarquias claras, não existe. Isso contradiz o senso comum de que a globalização homogeneiza as economias mundiais. As características econômicas dependem das especificidades de uma cidade ou região, influenciando e afetando fatores que não costumam ser facilmente reconhecidos. Sassen (2010) baseia suas afirmações na existência de dois conjuntos diferenciados que impulsionam a globalização:

[...] um deles supõe a formação de processos e instituições manifestamente globais como a OIT (Organização Internacional do Trabalho), os mercados financeiros globais, o novo cosmopolitismo e os tribunais penais internacionais. As práticas e as formas organizativas que permitem o funcionamento destas dinâmicas constituem aquilo que se considera global em um sentido mais típico do término. Entretanto, existe um segundo conjunto que necessariamente não correspondem a escala global em si mesma, porém de todas as formas formam parte da globalização. Se trata de certos processos que se dão no seio mais profundo dos territórios e os domínios institucionais considerados parte do nacional em quase todo mundo. Se bem que estes processos se encontram localizados em âmbitos nacionais, ou inclusive subnacionais, formam parte da globalização porque estão orientados até sistemas e programas globais. Se trata (sic) de redes e configurações multifacetadas e transfronteiriças que 
em alguns casos incluem ordens normativas e que conectam processos, instituições e atores subnacionais ou "nacionais", porém não necessariamente mediante o sistema formal interestatal [...] (p. 21-22).

Apesar da situação de dominação e exploração de vários séculos, muitos povos conseguiram sobreviver e caminham com novos projetos na construção de alternativas ao modelo dominante. Nesse contexto, Walsh (2005) recorda que é necessário decolonializar ${ }^{1}$, utilizando estratégia que vai além de uma transformação que implique deixar de ser colonializado, mas que aponte uma transformação, construção ou criação e que busque uma transição, superação e emancipação por meio de alternativas ${ }^{2}$.

Países como Equador e Bolívia buscaram novos paradigmas socioeconômicos na construção de um projeto de sociedade, designado como Bem Viver, ganhando importância pela ocorrência de novas constituições políticas. Nesse contexto, os movimentos sociais, desde temas como ecologia ao feminismo, recuperaram sua centralidade na vida das pessoas e na natureza, na defesa de direitos básicos, como educação, saúde e igualdade social.

Porém, não se tem ainda um esboço teóricometodológico de uma abordagem sobre o Bem Viver que sinalize o sentido do seu real significado. O conceito do Bem Viver, "Bien Vivir/Vivier Bien" surge na região andina na América do Sul - desde o sul da Venezuela ao norte da Argentina - e deriva por um lado, do Quechua (runa simi) e, por outro, do Aimara (aymará jaya mara aru), que são idiomas pré-hispânicos da região andina. Outras línguas indígenas, como os tupí-guaranis, também mencionam esse termo (Estermann, 2011).

O debate sobre a crise de caráter sistêmico e civilizatório sugere reflexão sobre o sentido de Bem Viver, o qual se relaciona a qualidade de vida e remete a questões como espiritualidade, natureza, modos de vida e consumo, política, ética. Nessa perspectiva, há necessidade de amadurecer o diálogo sobre o tema Bem Viver como uma proposta alternativa de desenvolvimento, quando se pensa a relação sociedade e natureza.

Nesse sentido, objetivou-se analisar a produção científica sobre o termo "Bem Viver" por meio de um estudo bibliométrico, com pesquisa bibliográfica e documental, e de uma discussão conceitual e que transpassa o tema na realidade social. Utilizou-se como técnica de medição a lei de Bradford, para descobrir a extensão na qual os artigos desse assunto científico específico aparecem em periódicos. Desenvolveu-se uma pesquisa sobre o tema "Bem Viver", "Buen Vivir/Vivir Bien" $e$ "Good Living" e suas aproximações com os temas "desenvolvimento," "bem comum" e/ou "bem estar subjetivo", "interculturalidade" e "transdisciplinaridade". As fontes bibliográficas de pesquisa foram as plataformas do Web of Science, Scielo e Portal de Periódicos da CAPES.

O resultado deste trabalho se divide em cinco partes adicionais, que começam com esta introdução; segue-se com uma pesquisa bibliográfica

\footnotetext{
${ }^{1}$ Os termos descolonialidade-descolonial para decolonialidade-decolonial foi uma supressão de Catherine Walsh. Para a autora, pretende-se marcar uma distinção com o significado em castelhano do "des" que pode ser entendido como um simples desarmar, desfazer o reverter do colonial. Nesse jogo linguístico, a autora se propõe evidenciar que não existe um estado nulo da colonialidade, senão posturas, posicionamentos, horizontes e projetos de resistir, transgredir, intervir, insurgir, crer e incidir. O decolonial denota, então, um caminho de luta contínuo no qual se pode identificar, visibilizar e encorajar "lugares" de exterioridade e construções alternativas (Walsh, 2012, p. 25).

${ }^{2}$ Nesse sentido, não descolonizar, pois não se quer desfazer ou desmanchar o colonial, não há como fingir que a colonização não existiu e apagar tudo que ela impôs. "O que se busca é uma luta constante, uma construção, a busca por alternativas, a fim de traçar um rumo novo para os povos" (Walsh, 2009, p. 14).
} 
sobre os temas Bem Viver e interculturalidade; transcidiplinaridade na visão do Bem Comum e/ ou Bem Estar Subjetivo; e Ecossocioeconomias: movimentos alternativos ao desenvolvimento e suas aproximações com o Bem Viver. A seguir, apresenta-se a metodologia com os critérios para seleção e análise dos artigos. Em continuação, apontam-se os resultados com a análise dos artigos selecionados. Finaliza-se com as considerações finais consideradas apropriadas a partir desta análise e, por fim, as referências deste estudo.

\section{Gênese e fundamentos conceituais}

\subsection{Bem Viver e interculturalidade}

Os termos Sumak Kawsai em Quechua, Suma Qamaã em Aymara ou Buen Vivir/Vivir Bien, na tradução mais difundida, representam uma cosmovisão construída por meio de muitos anos pelos povos altiplanos dos Andes, que se tornaram invisíveis frente ao colonialismo, patriarcalismo e capitalismo. Existem outros significados para o termo: em guaraní, "Teko Kavi" significa vida boa e viver bem (respeitar a vida). "Buen Vivir", para los Embera de Colômbia, é estar em harmonia entre todos.

Na República do Equador, as políticas do "Plan Nacional para el Buen Vivir (PNBV)" consideram: "[...] a atividade física, o ócio e a recreação como direitos do Bem Viver. A boa condição física e a possibilidade de desfrutar o tempo de ócio de qualidade são parte dos objetivos das políticas de saúde, inclusão social e cultura" (Tortosa-Martínez et al., 2014, p. 150-151). Nesse contexto, as instituições do setor social foram se reformulando para atender os mandatos constitucionais do Bem Viver e alcançar as metas e desafios do PNBV.
Em particular, o processo de implementação da equidade orientada para o sistema de proteção social, erradicação da pobreza e inclusão, exigem um esforço orçamental significativo e construção de consenso entre diversas instituições e agentes públicos e privados para permitir a reunião de esforços que convergem em um pacto social e fiscal que irá permitir-lhe viabilidade e sustentabilidade ao longo do tempo (CEPAL, 2014, p.10).

Nesse sentido, o Bem Viver relaciona-se à melhoria da qualidade de vida das pessoas (alimentação, vestimenta e habitação, por exemplo), o que se obtém por meio da educação, das relações familiares, trabalho, hábitos e ambiente, entendendo-se esse conceito como:

[...] um compromisso com a mudança [...] que permite a aplicação de um novo paradigma econômico, cujo final não se concentra no material, na acumulação mecanicista e interminável de bens, mas em vez disso promove uma estratégia econômica inclusiva, sustentável e democrática. [...] Além disso, Bem Viver' é construído [...] sobre a transição do atual antropocentrismo para o biopluralismo [...]. Finalmente, 'Bem Viver' também se baseia nas demandas por igualdade e justiça social, e no reconhecimento, avaliação e do diálogo dos povos e suas culturas, formas de conhecimento e modos de vida (SENPLADES, 2009, p. 10 - grifo dos autores).

O conceito surgiu há menos de uma década (Teijlingen \& Hogenboom, 2017) e tem sido referido como: filosofia de vida (Acosta, 2010), cosmologia (Walsh, 2010), atitude de vida (Cortez, 2011), ontologia (Thomson, 2011), modelo de desenvolvimento (Radcliffe, 2012) e alternativa ao desenvolvimento (Gudynas, 2011).

Para Gudynas (2011), trata-se de um conceito em construção e, devido a seu caráter relativista, faz-se necessário adequar sua aplicação a cada contexto cultural e ambiental. Nesse sentido, o 
"Bem Viver" é entendido como um paradigma que compreende um espaço-temporal comum, no qual podem conviver distintas ontologias, na construção de uma interculturalidade que aponte "alternativas ao desenvolvimento".

Nessa esteira, podem-se distinguir três correntes do Bem Viver: (1) a indigenista e pachamamista, (2) a socialista e estadista e (3) a pós-desenvolvimentista e ecologista. (Hidalgo-Capitán, 2012, p. 16).

A primeira e originaria seria a corrente indigenista e pachamamista, caracterizada pela relevância que se dá a autodeterminação dos povos indígenas na construção do Bem Viver, assim como aos elementos mágico-espirituais (la Pachamama). [...] Estaria vinculada com o pensamento indígena pré-moderno. [...] A segunda seria a corrente socialista e estadista, caracterizada pela relevância que dá a gestão política-estatal do Bem Viver, assim como aos elementos relativos a equidade social. [...] e a terceira seria a corrente post-desenvolvimentista e ecologista, caracterizada por relevância que se dá a construção participativa do Bem Viver, com a inclusão de aportes indigenistas, socialistas, feministas, teológicos e, sobretudo, ecologistas. Falam do Bem Viver como uma alternativa ao desenvolvimento, como uma utopia em construção [...].

A primeira corrente - indigenista e pachamamista - tem como seus principais representantes líderes indigenistas Kichwas equatorianos, aymaras bolivianos e quechuas peruanos, bem como alguns intelectuais indigenistas mestiços e brancos; a segunda corrente - socialista e estadista - é a que inspira a política dos governos do Equador e da Bolívia (sobre esta corrente, critica-se a falta de sensibilidade com os problemas ambientais, com as reivindicações dos povos indígenas e também sua defesa ao extrativismo); e a terceira corrente - pós-desenvolvimentista e ecologista - tem entre seus representantes intelectuais progressistas latino-americanos e europeus vinculados ao ecologismo e com outros movimentos sociais (Hidalgo-Capitán, 2014).

Conforme Acosta (2016, p.46), o discurso sobre desenvolvimento consolidou uma dominação dicotômica: “[...] desenvolvimento-subdesenvolvimento, pobre-rico, avançado-atrasado, civilizado-selvagem, centro-periferia". Desse modo, países considerados subdesenvolvidos aceitaram aplicar políticas, instrumentos e indicadores para sair do estereótipo de "atrasado" para chegar ao desejado "desenvolvimento". Muitas vezes, tais países negaram suas raízes históricas e culturais para sair dessa caracterização.

A colonialidade que marcou o padrão de relações no contexto da colonização europeia nas Américas ainda se constitui como modelo de poder moderno e permanente. Para Quijano (2000) e Walsh (2005), a colonialidade atravessa praticamente todos os aspectos da vida e se configura a partir da: (1) colonialidade do poder - refere-se ao estabelecimento de um sistema de classificação social baseado na categoria de "raça"; (2) colonialidade do saber - reporta-se à suposição de que a Europa se constituía como centro de produção do conhecimento; (3) colonialidade do ser - corresponde à subalternização e desumanização dos sujeitos colonizados; e (4) colonialidade da natureza e da própria vida - concerne à divisão binária natureza/ sociedade, em que se nega a relação milenar entre mundos biofísicos, humanos, espirituais, descartando-se o mágico-espiritual-social que dá sustentação aos sistemas integrais de vida e de conhecimento dos povos ancestrais.

Nesse sentido, "é a interculturalidade como processo e projeto social, político, ético e intelectual, que assume a decolonialidade como estratégia, ação e meta" (Walsh, 2005, p. 25). Assim, pode-se 
entender o pedagógico do decolonial como "[...] metodologias organizacionais, analíticas e psíquicas que orientam rupturas, transgressões, deslocamentos e inversões dos conceitos e práticas impostas e herdadas" (Walsh, 2012, p. 25).

A interculturalidade é central na (re)construção de um pensamento crítico de/desde outro modo, precisamente por três razões principais: primeiro, porque está concebida e pensada desde a experiência vivida pela colonialidade, quer dizer, desde o movimento indígena; segundo, porque reflete um pensamento não baseado nos legados eurocêntricos ou da modernidade; e terceiro, porque tem sua origem no sul, dando assim uma volta a geopolítica dominante do conhecimento que tem seu centro no norte global (Walsh, 2005, p. 25).

Para o Bem Viver, existe uma identidade cultural que emerge de uma relação profunda com o lugar onde se habita, no qual surgem modos de vida, expressões, como arte, dança, música, vestimenta, etc. Nesses termos, identidade sugere historicidade, viver o tempo presente a partir de uma memória, de uma ancestralidade, que projeta uma perspectiva de futuro possível de ser vivido (Mamani, 2010). Para Acosta (2016, p. 24-25),

A visão de mundo dos marginalizados pela história, particularmente dos povos e nacionalidades indígenas, é uma oportunidade para construir outros tipos de sociedades, sustentadas sobre uma convivência harmoniosa entre os seres humanos consigo mesmos e com a Natureza, a partir do reconhecimento dos diversos valores culturais existentes no planeta. $\mathrm{Ou}$ seja, trata-se de bem conviver em comunidade e na Natureza.

De certo modo, rompe-se com a perspectiva antropocêntrica, remetendo-se a uma visão ecocêntrica regulando efetivamente as relações sociedade- -natureza, com o objetivo de atenuar ou diminuir os impactos sobre os recursos naturais. Ante esse raciocínio, a concepção de que os recursos são inesgotáveis evidencia o modo de vida da sociedade de mercado, que sugere um mau desenvolvimento. Nesse sentido, no estudo das sociedades capitalistas, Marx (2008) afirma que a dinâmica das relações humanas no mundo físico condiciona a produção de ideias, vinculando a ideologia às condições materiais de produção.

As relações jurídicas, bem como as formas do Estado, não podem ser explicadas por si mesmas [...] essas relações têm, ao contrário, suas raízes nas condições materiais de existência [...]. Na produção social da própria existência, os homens entram em relações determinadas, necessárias, independentes da sua vontade; essas relações de produção correspondem a um grau determinado de desenvolvimento de suas forças produtivas materiais. A totalidade dessas relações de produção constitui a estrutura econômica da sociedade, a base real sobre a qual se eleva uma superestrutura jurídica e política e à qual correspondem formas sociais determinadas de consciência. O modo de produção da vida material condiciona o processo da vida social, política e intelectual. Não é a consciência dos homens que determina o seu ser; ao contrário, é o ser social que determina sua consciência (p. 47).

O que poderia afirmar, segundo a sociologia marxista, que a superestrutura (institucionalidade) é determinada pela infraestrutura (forças e relações de produção), ainda que o inverso possa parecer determinante como forma de prevalecer o status quo. Essa perspectiva se materializa no que se chama por sociedade de consumo.

Os autores que discutem Bem Viver questionam esse padrão produtivista e consumista como referência para dicotomizar a organização do planeta, como expressam os termos apontados acima. Ressalte-se que o Bem Viver não representa necessaria- 
mente uma maneira de pensar e atuar unicamente de povos originários, mas também por outros grupos autóctones espalhados pelo continente. É importante se dar conta de que há aprendizados, mesmo que esses modos de vidas não estejam muitas vezes associados com a modernidade e que façam ser repensado o próprio conceito de progresso.

$\mathrm{O}$ bem viver concede "[...] ênfase explícita à escala local-regional, considerando que esta é a mais adequada, tanto para expressar as resistências contra o desenvolvimento-globalização, quanto para concretizar as alternativas" (Garcia, 2012, p. 210). O conceito está inserido em uma determinada identidade cultural, com diversas expressões, mas com um núcleo unificador, uma essência em comum: “[...] o paradigma comunitário que tem como base a vida em harmonia e o equilíbrio do meio" (Mamani, 2010, p. 15)

Para Mignolo (2000), a matriz colonial tornou a lógica eurocêntrica e dominante como hegemônica e única perspectiva de conhecimento. Nesse sentido, fazem-se necessários e urgentes processos de decolonialização e despatriarcalização, assim como um diálogo com outras propostas alternativas (Pazos et al., 2014; Walsh, 2005; 2012).

[...] Bem Viver também respeita sua pluralidade interna de concepções, sem hierarquias. A abordagem liberal clássica de multiculturalidade é insuficiente para esse efeito. Por isso uma posição intercultural é seguida. Buen Vivir é mais do que uma simples coexistência ou justaposição de diferentes culturas, porque eles interagem no diálogo e prática focada na promoção de alternativas para desenvolvimento (Gudynas, 2011, p. 445, tradução dos autores).

Coadunando com Gudynas, a socióloga Catherine Walsh (2009) aponta que a definição de Bem
Viver é estabelecida por cada cultura. No entanto, a compreensão da interculturalidade é requisito para a prática do bem viver, mesmo porque não há como descolar individualidade de coletividade, isto é, ambas fazem parte de uma mesma dinâmica. Para Acosta (2016),

[...] o Bem Viver com sua proposta de harmonia com a Natureza, reciprocidade, relacionalidade, complementariedade e solidariedade entre os indivíduos e comunidades, com sua oposição ao conceito de acumulação perpétua, com seu regresso ao uso, o Bem Viver, enquanto ideia em construção, livre de preconceitos, abre as portas para formular visões alternativas de vida (p. 33).

O Bem Viver se constituiu em uma proposta e uma oportunidade para pensar outra realidade na qual os seres humanos formam parte de um todo mais harmônico com a natureza e com os outros seres humanos, com alteridade ${ }^{3}$ (De La Cuadra, 2015). Ao mesmo tempo, é um paradigma para orientar as políticas e ações dos Estados Nacionais, que devem regular as relações sociais com o fim de diminuir as desigualdades na sociedade e melhorar as condições de vida dos economicamente vulneráveis. Nesses termos, o diálogo em torno do Bem Viver sugere repensar a própria definição de desenvolvimento, relativizando-o, a partir do entendimento de interculturalidade.

\subsection{A transcidiplinaridade na visão do Bem Comum elou Bem-Estar Subjetivo}

Está em curso uma série de crises que, “[...] não é somente uma crise ecológica, senão uma crise

\footnotetext{
${ }^{3}$ Alteridade [...] "do latim alteritas. Ser outro, colocar-se ou constituir-se como outro" (Abbagnano, 2007 p. 34-35). Em outras palavras, implica que um indivíduo seja capaz de se colocar no lugar do outro, em uma relação baseada no diálogo e valorização das diferenças existentes.
} 
do modelo econômico civilizatório" (Mardones et al., 2015, p. 29). Para os autores, esta crise se manifesta na mudança climática e torna legítima nossa preocupação pelos poucos espaços saudáveis situados em áreas protegidas.

Durante a Assembleia Geral das Nações Unidas, na sessão 2008-2009, foi apresentado o conceito de "Bem Comum da Humanidade", como um instrumento nacional para a saída das múltiplas crises que afetavam a humanidade e o planeta. Para Houtart (2011), não se tratava de propor regulações ao sistema capitalista, mas também "[...] alternativas a sua lógica de criação de riquezas a custa de destruições ecológicas graves e de desigualdades sociais profundas" (p. 21).

O "Bem Comum da Humanidade" significa a produção e a reprodução da vida e serve de referência ou de parâmetro fundamental para a organização social humana e para a relação com a natureza. Trata-se de uma significação mais ampla que de "bens comuns" (commons), que são indispensáveis para satisfazer as necessidades da vida coletiva e pessoal, fortemente desmanteladas pelo neoliberalismo.

Nesse sentido, a discussão em torno do Bem Viver aponta a inviabilidade de se continuar reverenciando o atual modo de produção e consumo, concebido como um dispositivo legítimo de crescimento baseado na acumulação de bens materiais. Para o Bem Viver, diferentemente, a riqueza não consiste em ter e acumular a maior quantidade de bens possíveis, mas em lograr um equilíbrio entre as necessidades fundamentais da humanidade e os recursos disponíveis para satisfazê-las.

[...] o maior potencial do Buen vivir reside nas oportunidades que ele gera para o diálogo com outros discursos modernos e as formas atuais do desenvolvimento, ampliando o quadro dos debates atuais e permitindo a possibilidade de aparecimento de concepções inovadoras, instituições e práticas através da aprendizagem coletiva (Vanhulst \& Beling, 2014, p. 61, tradução dos autores).

Para Sen (2000), só se pode conseguir o bem-estar social e o desenvolvimento humano se as pessoas tiverem capacidade para articular e construir seus projetos de vida. O enfoque do desenvolvimento humano incorporou progressivamente dimensões socioculturais em suas análises, destacando a importância de políticas multiculturais que permitam manter e fortalecer a identidade de pessoas e grupos humanos, corrigindo injustiças historicamente enraizadas e socialmente arraigadas (PNUD, 2004).

Aqui, entra o diálogo transdisciplinar que permite a complementaridade entre as ciências naturais que se ocupam dos aspectos tangíveis do desenvolvimento e os aspectos intangíveis e imateriais presentes e cada vez mais importantes para se poder falar de processos de desenvolvimento desde o conhecimento tradicional das comunidades (Mardones et al., 2015).

A complexidade ambiental requisita, portanto, uma reestruturação na forma como os valores humanos têm influído no conhecimento do mundo, buscando-se equilibrar o aspecto racional e moral (Leff, 2001). Desse modo, o diálogo entre saberes científicos e culturais e a inserção da subjetividade, questionando os valores e interesses predominantes nas tomadas de decisão e estratégias de apropriação da natureza, motiva-nos a refletir sobre a natureza do ser, do saber e do conhecer. Segundo o pensamento da complexidade, é necessário ultrapassar a condição existencial individual do ser, como aspecto original do ser humano, e buscar o significado das identidades coletivas, construídas a partir da diversidade cultural e da diferença, revalorizando-as.

Para Morin (2005), são necessárias competência teórica, clareza epistemológica e metodológica e 
uma consciência transdisciplinar para que possamos verdadeiramente responder, neste milênio, aos três grandes desafios que estão relacionados: processos de construção, desconstrução e reconstrução do conhecimento humano; formação de cidadãos e não apenas indivíduos e; desenvolvimento da consciência, como condição fundamental para a sobrevivência da humanidade. Três eixos norteiam a visão transdisciplinar:

[...] a Atitude Transdisciplinar busca a compreensão da complexidade do nosso universo, da complexidade das relações entre sujeitos, dos sujeitos consigo mesmos e com os objetos que os circundam, a fim de recuperar os sentidos da relação enigmática do ser humano com a Realidade - a Pesquisa Transdisciplinar pressupõe uma pluralidade epistemológica. Requer a integração de processos dialéticos e dialógicos que emergem da pesquisa e mantém o conhecimento como sistema aberto; - a Ação Transdisciplinar propõe a articulação da formação do ser humano na sua relação com o mundo (ecoformação), com os outros (hetero e co-formação), consigo mesmo (autoformação), com o ser (ontoformação), e, também, com o conhecimento formal e o não formal. Procura uma mediação dos conflitos que emergem no contexto local e global, visando a paz e a colaboração entre as pessoas e entre as culturas, mas sem desconsiderar os contraditórios e a valorização de sua expressão (Nicolescu, 2005).

De acordo com Acosta (2016), a busca de novas formas de vida implica revitalizar a discussão política, ofuscada pela visão economicista sobre fins e meios, na qual a resolução dos problemas exige a aproximação transdisciplinar, tendo como parâmetro complexidades múltiplas que não podem ser resolvidas com visões monocausais. Leff coaduna com Acosta, afirmando que,

[...] o saber ambiental e o diálogo de saberes emergem do questionamento de saber a origem da crise ambiental que se retorna a problemática da vida moderna e tradicional e questiona a centralidade, a universalidade de um saber totalizante ordenador do processo de globalização (Leff, 2004, p. 310).

Os saberes ambientais contribuem para manutenção da biodiversidade e derivam em grande parte do saber fazer que se perpetua no tempo, resultado das experimentações e observações individuais ou de grupos. Esse saber fazer, em sua maioria, é domínio dos mais velhos, presumindo-se a experiência acumulada no convívio e troca com o meio onde se vive (Davis \& Wagner, 2003). Essa proposta pedagógica tem origem na educação popular de Paulo Freire (2012), a partir da crítica à ordem social e do papel integrador da educação tradicional e identificada com a necessidade de transformação social. Para Carrillo (2003, p. 206), esse reconhecimento se faz presente na educação campesina e indígena, "[...] na densidade histórica e cultural dos sujeitos educativos e, por tanto, na necessidade de reconhecer as histórias locais e organizativas de onde se localizam os trabalhos educativos [...]". "[...] na reconstrução crítica da experiência vivida, em sua sistematização".

Apesar de proceder de visões consideradas utópicas por muitos, o bem viver, como alternativa de desenvolvimento, exibe uma série de características comuns a partir das quais surge um "modo de vida alternativo em substituição àquele desenvolvimento que assumido pelas sociedades ocidentais e que frente a atual crise ambiental, resulta insustentável" (Acosta, 2012, p. 68; Acosta et al., 2013, p. 309).

Na perspectiva do bem viver, os povos indígenas originários questionam o termo desenvolvimento e tudo o que ele implica, já que para nossos povos e comunidades, ele têm significado a degradação da natureza e a destruição das nossas comunidades. $\mathrm{O}$ termo desenvolvimento está ligado á exploração, 
à marginalização, à depredação e à dependência, pois segundo a lógica ocidental, o desenvolvimento implica em ganhar, em desfavor do outro (Mamani, 2010, p.36)

O que se percebe é que o desenvolvimento tem se sustentado em uma perspectiva antropocêntrica e instrumental da natureza e em uma concepção de vida baseada na acumulação e no aproveitamento de bens materiais que se traduzem no crescimento econômico, na produção e no consumo ilimitado (Brand \& Wissen, 2013, p. 446-447).

Nesse sentido, abordagens de desenvolvimento como o Bem Viver - apesar de apresentar um cunho filosófico utópico mais do que uma proposta de mudanças concretas; mais inspiração do que uma revolução no modo de pensar; mais sonho do que realidade -, demonstram, sem dúvida, uma possibilidade de resistência ao modo de vida questionável predominante da sociedade, propondo um novo arcabouço cultural, centrado no equilíbrio, bem-estar e sustentabilidade.

\subsection{Ecossocioeconomias: movimentos alternativos ao desenvolvimento e suas aproximações com o Bem Viver}

No contexto de movimentos alternativos de desenvolvimento, surgem as ecossocioeconomias, apontadas por Sachs (2007), que ocorrem no mundo da vida, nas experiências empíricas nas comunidades, povoados, onde os problemas e as soluções acontecem e nem sempre são devidamente qualificados (Sampaio, 2015). Trata-se de uma teoria pensada, partindo-se das experimentações e da complexidade do cotidiano (Mancebo \& Sachs, 2015).

Embora haja um esforço de compreensão de como sinalizar experiências de ecossocioeconomia a partir de indicadores (Sampaio, 2010), a tarefa se apresenta complexa, buscando incorporar dados subjetivos, o que pode sugerir maior dificuldade de mensuração.

\begin{abstract}
Significa, demais, reconhecer a incompletude e insuficiência das teorias econômicas e sociais que serviram de sustentação e orientação aos processos de desenvolvimento até o presente. Significa tomar consciência, concretamente, de que em um mundo cada vez mais heterogêneo por sua crescente e inevitável interdependência, a aplicação de modelos de desenvolvimento sustentado em teorias mecanicistas acompanhados de indicadores agregados e homogeneizantes, representa uma rota segura até novas e mais inquietantes frustações (Max-Neef et al., 1986, p. 15).
\end{abstract}

Nesse sentido, a ecossocioeconomia é uma forma possível de descortinar espaços alternativos de regeneração cultural, em sintonia com os princípios (interdependentes) de endogeneidade, equidade social e prudência ecológica. O termo surgiu no contexto de uma nova economia de sistemas socioecológicos complexos, cunhado por Karl William Kapp (1987), socioeconomista de origem alemã e um dos mais brilhantes precursores do debate ecológico-político europeu dos anos 1970. A ecossocioeconomia apresenta-se como uma alternativa ao desenvolvimento territorial sustentável, bem como privilegia modos de vidas tradicionais e suas experiências em curso.

No que concerne à produção de indicadores de aferição, destacam-se os esforços de Amartya Sen (2000) para viabilizar o Índice de Desenvolvimento Humano (IDH), editado pelas Nações Unidas, e os indicadores de Desenvolvimento à Escala Humana dos chilenos Max-Neef et al., (1986), índice que resulta do cruzamento de nove necessidades humanas básicas axiológicas: subsistência, proteção, afeto, compreensão, participação, criação, diversão, identidade e liberdade, e de quatro necessidades 
existenciais: ser, ter, fazer e estar. A partir dessa matriz, propõe-se a construção de indicadores subjetivos que sejam capazes de permitir o diagnóstico, planificação e avaliação.

Outro exemplo é o Índice do Planeta Feliz, criado pela organização britânica The New Economics Foundation, que se baseia em três indicadores: esperança de vida ao nascer, satisfação com a vida (bem-estar subjetivo) e pegada ecológica. A partir desse índice, infere-se que é possível ter alto nível de bem-estar subjetivo sem excessivo consumo.

Mas o que mais se assemelha ao conceito do "Buen Vivir" é o índice de "Felicidade Interna Bruta", elaborado por um país budista localizado no Himalaia, Butão, que assume uma concepção de vida inspirada em conceitos muito próximos do Bem Viver. As quatro dimensões avaliadas são a autossuficiência econômica, preservação do meio ambiente, promoção cultural e boa governança (Thinley, 1998).

$\mathrm{Na}$ Europa, existem algumas iniciativas para superar o consumismo, derivado do capitalismo desregulado, como, por exemplo, o decrescimento, cuja origem é comum aos problemas que estão sofrendo as sociedades e o planeta, como o atual estado de desenvolvimento que tem levado o planeta a uma soma de múltiplas crises (energética, econômica, humanitária, ecológica e social). Teoricamente, o decrescimento tem seus fundamentos na bioeconomia ${ }^{4}$ (ou economia ecológica) de Georgescu-Roegen (1971) e na filosofia ${ }^{5}$ de Ivan Illich (2004), incorporando outros elementos como, a crítica socioeconômica e antropológica do desenvolvimento, doutrinas do pós-desenvolvimento e outras ${ }^{6}$ (Garcia, 2012).

A ideia do decrescimento "[...] se intensificou durante a primeira metade (sic) do século XXI, quando se percebeu que os limites naturais do crescimento haviam sido excedidos [...]" Garcia (2012, p. 204). Serge Latouche (2009) é um dos principais teóricos dessa proposta. Para ele: “[...] não é verdadeiramente uma alternativa, concreta; seria, mais bem, a matriz que daria lugar a eclosão de múltiplas alternativas" (p. 137).

Para Latouche (2009), o decrescimento supõe um caminho de (des)aprendizagem, da necessidade de se desprender de um modo de vida equivocado e incompatível com a capacidade do planeta. Para que isso aconteça, o autor enuncia oito pilares de ações necessárias: reavaliar - nossos valores; reconceitualizar - construção social; reestruturar - os aparelhos econômicos e produtivos; redistribuir - acesso aos recursos naturais e de riqueza; recolocar-consumir localmente; reduzir - o consumo e o gasto energético; reutilizar - todos os objetos; e reciclar - em qualquer atividade.

Ressaltem-se outras ecossocioeconomias, como o "Slow", que é uma revolução cultural que questiona a velocidade do ritmo de vida. O termo slow, etimologicamente, significa lento, o que sugere visão de mundo associada ao uso do tempo substantivo, não que se abstraia a lógica instrumental tão necessária à economia, mas que não seja ela hegemônica ou mesmo determinante nos processos

\footnotetext{
${ }^{4}$ Aquela parte das atividades econômicas que captura valor a partir de processos biológicos e biorrecursos para produzir saúde, crescimento e desenvolvimento sustentável" (OCDE, 2006).

${ }^{5}$ Ivan Illich tinha uma visão crítica do sistema econômico e social que, nos anos noventa, encontrou outros colaboradores como Vandana Shiva e Serge Latouche.

${ }^{6}$ Essas abordagens se caracterizam, por um lado, por insistir na afirmação de que uma situacão de transbordamento é insustentável, logo, transitória; por outra parte, por afirmar que é então preciso buscar respostas para os problemas sociais e políticos fora do paradigma do desenvolvimento (Garcia, 2012, p. 207-208).
} 
de produção humana (Mayer, 2006; Sampaio et al., 2014; Honoré, 2005; 2012; 2013).

O Movimento Slow Cities surge em 1999, por meio de uma ideia inicial do então prefeito de Greve in Chianti, Paolo Saturnini. O modelo consistia em considerar a própria cidade, sua vocação natural ao turismo a partir de suas tradições, pensando-se em um modo alternativo de desenvolvimento, com base na melhoria da qualidade de vida do próprio autóctone, para que então possa recepcionar os visitantes a partir da convivialidade, o que levou a difundir os preceitos da Associação Città Slow em nível mundial (Mayer, 2006).

A filosofia "Slow" propõe, assim, que não se deve fazer tudo de forma lenta, mas na velocidade adequada ao ritmo da vida, o que corresponde realizar as atividades de forma satisfatória e com qualidade (Honoré, 2013). O modo de estar slow é uma atitude que pode se aplicar à vida em geral, desde a saúde e ambiente, alimentação, família, trabalho, lazer, educação, vida nas cidades e comunidades à luta contra as discriminações e contra a pobreza, valorizando-se a restauração do equilíbrio dos ritmos biológicos, laços sociais e valores essenciais do ser humano (Honoré, 2012, 2013). Como destacam Chalofsky \& Cavallaro (2013, p. 335) “[...] a emoção está no caminho, não no destino alcançado".

Podem-se citar outros desdobramentos desse movimento, como os relacionados à educação, abordados pelo "Slow Schools" e "Slow Education". Nesse sentido, compreendem as escolas que trazem o movimento de "Slow Food", que segue o conceito da ecogastronomia e preza o respeito pelas culinárias locais, preservação das sementes e plantas e o cuidado com animais dentro de uma determina- da ecorregião; e o "Slow Living", cujo movimento busca combater a aceleração do tempo, por meio do estabelecimento de conexões entre pessoas e em relação ao ambiente (Batista et al., 2013).

A proposta do movimento "Slow" pode ser analisada como uma tentativa de resistência aos modos de vida da contemporaneidade, resistindo-se aos imperativos da vida "líquido-moderna" (Bauman, 2004).

Outro exemplo é a Economia Solidária, que surge como um modo de produção e distribuição amparado por valores éticos, "criado e recriado pelos que se encontram (ou temem ficar) marginalizados do mercado de trabalho". Reúne "o princípio da 'unidade entre posse e uso' dos meios de produção e distribuição... com o 'princípio da socialização destes meios" (Singer, 2000, p. 12-14).

$\mathrm{O}$ artigo 25 da Declaração Universal dos Direitos Humanos dispõe que toda pessoa tenha direito a um nível de vida adequado que lhe assegure saúde e bem-estar e em especial, alimentação. Assim, a Via Campesina introduziu o conceito de soberania alimentar pela primeira vez na Cúpula Mundial da Alimentação (FAO, 2006), celebrada em Roma. A soberania alimentar é alternativa que se soma a outras muitas para enfrentar o modelo dominante propondo um novo sistema de relações entre grupos sociais (povos, nações, grupos raciais e étnicos, classes sociais); entre homens e mulheres; entre campo e cidade; entre produção e consumo; entre o Norte e o Sul; entre as nossas e as gerações seguintes; e, em definitivo, entre as pessoas e a natureza (Pazos et al., 2014).

A soberania alimentar é um direito dos povos de definir suas próprias políticas agropecuárias para

\footnotetext{
${ }^{7}$ A vida líquida é uma vida precária, vivida em condições de incerteza constante, é uma sucessão de reinícios. Nessa vida, livrar-se das coisas tem prioridade sobre adquiri-las (Bauman, 2004, p. 8). [...] é uma vida de consumo, projeta o mundo e seus fragmentos como objetos de consumo, ou seja, que perdem a sua utilidade enquanto são usados (Bauman, 2004, p. 16-17).
} 
a produção alimentar, além de proteger e regulamentar a produção e seus mercados domésticos. Desenvolve um modelo de produção campesino e sustentável que favorece as comunidades e seu meio ambiente. León \& Senra (2009, p. 11) definem que a soberania alimentar deve:

Priorizar a produção agrícola local para alimentar a população, o acesso aos campesinos e campesinas e dos e das sem terra e da terra, a água, as sementes e o crédito. Dai a necessidade de reformas agrárias, da luta contra os organismos geneticamente modificados, o livre acesso as sementes, o mantimento da água e sua qualidade de bem público que se reparta de forma sustentável.

Outro modelo é o Turismo Alternativo, mais especificamente o comunitário, cujas contribuições remetem à inclusão social e autonomia comunitária (Martins et al., 2014).

O turismo comunitário, solidário e sustentável apresenta-se como estratégia de sobrevivência e comunicação social de conservação de modos de vida e preservação de biodiversidade, organizado associativamente em territórios, como arranjos socioprodutivos e políticos de base comunitária, que se valem do consumo solidário de bens e serviços (Sampaio et al., 2011, p. 27).

Para Coriolano (2003, p. 41), o turismo comunitário pode ser definido como aquele "[...] desenvolvido pelos próprios moradores de um lugar que passaram a ser articuladores e os construtores da cadeia produtiva, onde a renda e o lucro ficam na comunidade e contribuem para melhorar a qualidade de vida". Nesse sentido, representa uma abordagem de desenvolvimento, uma vez que promove novas oportunidades de desenvolvimento local.

As propostas e iniciativas surgidas foram criadas como alternativas ao desenvolvimento ou, ainda, como vias alternativas de desenvolvimento, dentro do princípio da sustentabilidade. Para Garcia (2012, p. 209), essas alternativas dão:

[...] ênfase á escala local-regional como sendo a mais adequada, tanto para expressar as resistências contra o desenvolvimento, quanto para concretizar as alternativas[...]"; [...] reivindicam autonomia, tanto perante o mercado quanto perante o Estado; quer fundamentada na associação, quer na comunidade"; “[...] trata-se de insistir na diversidade cultural [...].

Nesse sentido, segundo Gudynas \& Acosta (2008), somam-se iniciativas para avançar nas concepções de desenvolvimento, desenhando indicadores de Bem Viver e discutindo as relações com outras aproximações, como as da economia social e solidária, "Slow", turismo alternativo e aquelas enfocadas no bem-estar e na felicidade ou justiça. São alternativas que não devem ser entendidas como contrapropostas, ao contrário, percebe-se, em vários momentos, que possuem pontos em comum. Ainda que partindo sempre de diferentes realidades, são complementares, porque somam esforços e enriquecem a visão de um modelo que queremos alcançar.

\section{Metodologia}

Para este artigo, foi realizado um estudo bibliométrico como técnica quantitativa e estatística de medição dos índices de produção e disseminação do conhecimento científico "[...] tal como procede a demografia ao recensear a população" (Fonseca, 1986, p. 10), que surge no início do século como sintoma da necessidade do estudo e da avaliação das atividades de produção e comunicação científica.

Como métodos de medição da produtividade, temos três técnicas de medição: lei de produtividade de autores de Lotka (1926); lei de dispersão do co- 
nhecimento científico de Bradford (1934) e o modelo de distribuição e frequência de palavras num texto de Zipf (1949). Neste artigo, utilizou-se a Lei de dispersão do conhecimento científico de Bradford, técnica cujo objetivo é descobrir a extensão na qual artigos de um assunto científico específico aparecem em periódicos. A presente pesquisa reveste-se de importância pelo fato de analisar dados sobre a produção científica que aborda o tema em questão (Araújo, 2006). Nesse caso, foram encontrados e analisados 66 artigos.

Quanto aos procedimentos, enquadra-se como bibliográfica desenvolvida com base em artigos científicos publicados em periódicos internacionais e nacionais, realizada a partir do levantamento de referências teóricas já analisadas e publicadas por meios escritos e eletrônicos, como livros, artigos científicos, páginas de web sites; e documental, recorrendo-se a fontes mais diversificadas e dispersas, sem tratamento analítico, tais como: tabelas estatísticas, jornais, revistas, relatórios, documentos oficiais, com ampla discussão conceitual e teórica (Tabela 1).

TABELA 1 - Tipo de pesquisa e objetivos.

\begin{tabular}{|c|c|}
\hline Tipo de pesquisa & Objetivos \\
\hline Pesquisa Bibliométrica & $\begin{array}{l}\text { Descobrir a extensão, abrangência e } \\
\text { divulgação de artigos que mencionam } \\
\text { o tema do "Bem Viver", "Bien Vivir / } \\
\text { Vivir Bien" e "Good Living" no título, } \\
\text { introdução, resumo e palavras-chave. }\end{array}$ \\
\hline Pesquisa Bibliográfica & $\begin{array}{l}\text { Conhecer e analisar conceitos, teorias e } \\
\text { posições de autores que discutem o tema } \\
\text { do "Bem Viver". }\end{array}$ \\
\hline Pesquisa Documental & $\begin{array}{l}\text { Conhecer conceitos, normas e propostas } \\
\text { institucionais sobre o tema do "Bem Vi- } \\
\text { ver, discutidos no texto, contidos em do- } \\
\text { cumentos como das Nações Unidas, Plan } \\
\text { Nacional para el Buen Vivir (PNBV), } \\
\text { SENPLADES, Plataforma Web of Scien- } \\
\text { ce, SciELO e Portal de Periódicos da } \\
\text { CAPES. }\end{array}$ \\
\hline
\end{tabular}

FONTE: construção dos autores

\subsection{Critérios para seleção e análise dos artigos}

Pesquisou-se nos periódicos com as palavras de busca: "Bem Viver", "Bien Vivir / Vivir Bien" e "Good Living" no título, introdução, resumo e palavras-chave. As palavras encontradas mais associadas ao tema foram: ““desenvolvimento," "bem comum" e/ou "bem estar subjetivo", "interculturalidade" e "transdisciplinaridade". A pesquisa dos artigos foi realizada no período de janeiro a fevereiro de 2016, na plataforma Web of Science, SciELO e Portal de Periódicos da CAPES. Como resultado, analisou-se 66 artigos, sendo 63 internacionais e três nacionais.

Identificaram-se os periódicos que enfatizam o tema do Bem Viver no conceito originário Sumak Kawsai em Quechua, Suma Qamaã em Aymara, Buen Vivir/Vivir Bien (Equador e Colômbia) e Vida Boa (Guaraní), demonstrando-se as várias etimologias das expressões.

Para desenvolver a base de dados, utilizou-se o Software Excel ${ }^{\circledR}$. Elaboraram-se quatro planilhas: (1) Ano de publicação dos artigos; (2) Periódicos e número de publicações; (3) Revistas-Áreas-Eventos de Publicação 2013-2014; e (4) Procedimentos Metodológicos. Os dados estabelecidos para análise foram: publicações por ano; identificação das áreas de maior publicação; periódicos e, no final, autores mais citados.

Para a identificação da área, ano de publicação, periódicos publicados e autores mais citados, efetuou-se a leitura do resumo e, quando não mencionadas essas informações, partiu-se para a leitura da introdução e do item referente à metodologia, bem como das referências de cada artigo. A seguir, apresenta-se a análise da pesquisa realizada. 


\section{Resultados: análise dos artigos selecionados}

Foram pesquisados 66 artigos, dos quais 61 na língua espanhola, três na língua portuguesa, um em inglês e um em italiano. $\mathrm{O}$ corte do estudo foi longitudinal. O período das publicações analisadas compreendeu os anos entre 2001 a 2015 (Tabela 2). Os anos de maior publicação foram 2015 , com $36 \%$; 2014, com $21 \%$ das publicações, e 2013, com $11 \%$, o que demonstra que o interesse sobre o tema é recente e crescente.

TABELA 2 - Ano de publicação dos artigos.

\begin{tabular}{ccc}
\hline Ano de publicação & N. de artigos publicados & $\mathbf{\%}$ \\
\hline 2015 & 24 & 36.37 \\
2014 & 14 & 21.21 \\
2013 & 7 & 10.60 \\
2012 & 5 & 7.58 \\
2011 & 5 & 7.58 \\
2010 & 3 & 4.55 \\
2007 & 3 & 4.55 \\
2009 & 2 & 3.03 \\
2005 & 1 & 1.51 \\
2004 & 1 & 1.51 \\
2001 & 1 & 1.51 \\
TOTAL & $\mathbf{6 6}$ & $\mathbf{1 0 0}$ \\
\hline
\end{tabular}

FONTE: construção dos autores

Na Tabela 3, demonstra-se que a revista de maior publicação foi a Revista Polis, com 16 publicações (24.27\%). Os outros temas estão divididos em periódicos multidisciplinares, em proporções menores. A maioria das publicações são de periódicos da região da América Latina, na língua espanhola.
TABELA 3 - Periódicos e número de publicações.

\begin{tabular}{|c|c|c|}
\hline Periódicos & $\begin{array}{c}\text { N. de } \\
\text { publicações }\end{array}$ & $\%$ \\
\hline Polis & 16 & 24.27 \\
\hline Revista Cubana de Salud Pública & 4 & 6.08 \\
\hline Ingeniería Industrial & 3 & 4.57 \\
\hline Revista Crítica de Ciências Sociais & 2 & 3.05 \\
\hline Entramado & 2 & 3.05 \\
\hline Revista Integra Educativa & 2 & 3.05 \\
\hline Papeles de población & 2 & 3.05 \\
\hline Salud Colectiva & 2 & 3.05 \\
\hline Revista Latino Americana de Enfermagem & 1 & 1.51 \\
\hline $\begin{array}{l}\text { SMAD Revista Eletrônica saúde mental álcool } \\
\text { e drogas }\end{array}$ & 1 & 1.51 \\
\hline Investigación y Postgrado & 1 & 1.51 \\
\hline Revista Cubana de Enfermería & 1 & 1.51 \\
\hline Acta Médica Costarricense & 1 & 1.51 \\
\hline Luna Azul & 1 & 1.51 \\
\hline Revista Salud Uninorte & 1 & 1.51 \\
\hline Convergencia & 1 & 1.51 \\
\hline Producción + Limpia & 1 & 1.51 \\
\hline Discusiones Filosóficas & 1 & 1.51 \\
\hline Universum (Talca) & 1 & 1.51 \\
\hline História Crítica & 1 & 1.51 \\
\hline Argos & 1 & 1.51 \\
\hline Revista Brasileira de Estudos de População & 1 & 1.51 \\
\hline $\begin{array}{l}\text { Revista de la Sociedad Española de Enfermería } \\
\text { Nefrológica }\end{array}$ & 1 & 1.51 \\
\hline MEDISAN & 1 & 1.51 \\
\hline Ciencia \& Trabajo & 1 & 1.51 \\
\hline $\begin{array}{l}\text { CONfines de relaciones Internacionales y } \\
\text { ciencia política }\end{array}$ & 1 & 1.51 \\
\hline Latinoamérica & 1 & 1.51 \\
\hline Revista Finanzas y Política Económica & 1 & 1.51 \\
\hline Palavra Clave (online) & 1 & 1.51 \\
\hline Problemas del desarollo & 1 & 1.51 \\
\hline Tla-melaua & 1 & 1.51 \\
\hline Temas y Debates & 1 & 1.51 \\
\hline Investigación en Educación Médica & 1 & 1.51 \\
\hline Punto Cero & 1 & 1.51 \\
\hline Universitas Humanística & 1 & 1.51 \\
\hline Sinéctica & 1 & 1.51 \\
\hline Ambiente \& Sociedade & 1 & 1.51 \\
\hline Revista Cubana de Educación Superior & 1 & 1.51 \\
\hline Boletín Mexicano de derecho comparado & 1 & 1.51 \\
\hline Revista de la Faculdad de Medicina & 1 & 1.51 \\
\hline Sophia & 1 & 1.51 \\
\hline Total & 66 & 100 \\
\hline
\end{tabular}

NOTA: construção dos autores 
Na Tabela 4, foram levantados somente os periódicos que enfatizam o tema do Bem Viver no conceito originário, como mencionado anteriormente. Dos 66 artigos pesquisados, percebeu-se que o conceito original do Bem Viver foi publicado em 24 artigos (40\%), em áreas multidisciplinares como: Educação/Ensino, Interdisciplinar, Psicologia,
Antropologia/arqueologia, História, Sociologia, Planejamento Urbano e Regional/Demografia, Geografia, Ciências Socias Aplicadas, Ciências Ambientais e Direito, enquanto 10 artigos (15.15\%) foram publicados em áreas de saúde como: Medicina, Enfermagem e Psicologia.

TABELA 4 - Revistas-Áreas-Eventos de Publicação 2014.

\begin{tabular}{|c|c|c|c|c|}
\hline Revista & Áreas & Qualis & N. publicações & $\%$ \\
\hline \multirow[t]{3}{*}{ Polis } & Educação & $\mathrm{B} 1$ & & \\
\hline & Interdisciplinar & $\mathrm{B} 1$ & & \\
\hline & & & 16 & 47.05 \\
\hline \multirow[t]{3}{*}{ Revista Crítica de Ciências Sociais } & Antropologia/Arqueologia & $\mathrm{B} 1$ & & \\
\hline & História & $\mathrm{B} 1$ & & \\
\hline & & & 2 & 5.89 \\
\hline \multirow[t]{4}{*}{ Revista Brasileira de Estudos de População (Impresso) } & História & A2 & & \\
\hline & Interdisciplinar & $\mathrm{A} 2$ & & \\
\hline & Planejamento Urbano e Regional/ Demografia & $\mathrm{A} 2$ & & \\
\hline & Geografia & A2 & & \\
\hline Ciência \& Trabajo (En Línea) & Psicologia & $\mathrm{B} 1$ & 1 & 2.94 \\
\hline \multirow[t]{4}{*}{ Ambiente e Sociedade } & Ciências Ambientais & A2 & & \\
\hline & Educação & $\mathrm{B} 1$ & & \\
\hline & Interdisciplinar & $\mathrm{A} 2$ & & \\
\hline & & & 1 & 2.94 \\
\hline Palavra-clave & Ciências Sociais Aplicadas & $\mathrm{A} 2$ & 1 & 2.94 \\
\hline Revista Cubana de Salud Pûblica & Direito & $\mathrm{B} 1$ & 4 & 11.77 \\
\hline Ciencia \& Trabajo (En Línea) & Psicologia & $\mathrm{B} 1$ & 1 & 2.94 \\
\hline Universitas Humanística & Sociologia & $\mathrm{B} 1$ & 1 & 2.94 \\
\hline Salud Colectiva & Saúde Coletiva & B2 & 2 & 5.89 \\
\hline \multirow{3}{*}{ Revista Latino-Americana de Enfermagem (Online) } & Ensino & $\mathrm{B} 1$ & & \\
\hline & Psicologia & $\mathrm{A} 2$ & & \\
\hline & & & 1 & 2.94 \\
\hline Total & & & 34 & 100 \\
\hline
\end{tabular}

FONTE: construção dos autores. 
Quanto aos procedimentos metodológicos utilizados nos artigos analisados (Tabela 5), constatou-se que, em 53\%, com base na natureza e abordagem da pesquisa, utilizou-se de análise documental, do ponto de vista dos procedimentos técnicos de pesquisa documental; quanto aos objetivos, as pesquisas foram bibliográficas. De outro lado, em $29 \%$, utilizou-se, quanto à natureza e abordagem da pesquisa, da observação de campo; quanto aos procedimentos técnicos, recorreu-se à coleta de dados, com base nos objetivos de pesquisa descritiva.

Finalmente, em 18\%, utilizou-se, na natureza e abordagem da pesquisa, de entrevistas semiestruturadas; quanto aos procedimentos técnicos, estudo de caso, com base nos objetivos de pesquisa exploratória. A maior parte dos artigos (53\%) resultou de pesquisa biliográfica e/ou pesquisa documental; $47 \%$ das pesquisas utilizaram-se de práticas como a coleta de dados e estudos de caso, por meio de questionários semiestruturados, pesquisa-ação e/ou observação participante.

No que tange aos autores mais citados nos artigos, o autor com maior número de citações foi Eduardo Gudynas (40 citações), seguido de Alberto Acosta (43) e de Boaventura de Souza Santos (15 citações).

\section{Considerações finais}

Por meio de um estudo bibliométrico, infere-se que o tema do Bem Viver, independentemente da sua etimologia, possui um debate recente e crescente, que se acentuou nos últimos anos. Igualmente, por meio da leitura dos resumos, introdução e periódicos, identificou-se que o tema Bem Viver não faz referência ao paradigma desenvolvimentista fundamentado na acumulação de riqueza, crescimento econômico, produção e consumo ilimitado.

Igualmente, a pesquisa demonstrou que as áreas de avaliação relacionadas diretamente ao "Bem Viver", "Buen Vivir/Vivir Bien" e "Good Living” são multidisciplinares, demonstrando a transdisciplinaridade do tema. Percebeu-se que o Bem Viver, mais do que uma condição material, socioeducacional ou de saúde, é um estado particular de felicidade, no qual vigoram padrões culturais distintos.

Percebeu-se que, na área de saúde, o tema é discutido com significado mais próximo à qualidade de vida da pessoa, relacionada à condição física e mental, enquanto que as outras áreas relacionam o tema do Bem Viver ao respeito à vida, representando uma cosmovisão construída ao longo de muitos anos pelos povos Andinos.

Os temas bem viver e qualidade de vida são próximos, apesar de haver diferenças subjetivas e objetivas em suas concepções, pelo fato de que ambos requerem um parâmetro conhecido como "bem comum", incorporando a dimensão social, ambiental e política. Entretanto, a intersubjetividade presente no Bem Viver transcende o valor instru-

TABELA 5 - Procedimentos metodológicos utilizados nos artigos analisados.

\begin{tabular}{ccccc}
\hline Natureza e abordagem da pesquisa & Procedimentos técnicos & Objetivos & N. de artigos & \% \\
\hline Análise documental & Pesquisa documental & Bibliográfica & 35 & 53.03 \\
Observação de Campo & Coleta de dados & Descritiva & 19 & 12 \\
Entrevistas & Estudo de caso & Exploratória & $\mathbf{6 6}$ \\
TOTAL & & & $\mathbf{6 0}$ \\
\hline
\end{tabular}

FONTE: construção dos autores 
mental da qualidade de vida, formado por símbolos, significados e sentidos coletivos que não pertencem unicamente a alguém, mas por uma comunidade.

Portanto, a concepção do Bem Viver enaltece o fortalecimento das relações comunitárias e solidárias, os espaços comuns e as mais diversas formas de viver coletivamente, respeitando a diversidade e a natureza. Reconhece a diversidade de povos e suas estruturas e rompe com os velhos estados-nação dos setores privados-capitalistas como estruturas únicas, abrindo possibilidades para deixar para trás o extrativismo desenfreado e dar maior peso aos modelos cooperativos e comunitários. Harmoniza as necessidades da população à conservação da vida, diversidade biológica e equilíbrio de todos os sistemas de vida.

Não se pode negar a importância de movimentos alternativos como os citados no texto, os quais, apesar da resistência ao seu cunho filosófico utópico, representam iniciativas que promovem outros modos de vida e de se relacionar entre si e com a natureza, muitos similares ao conceito do Bem Viver. Todos se apresentam como projetos de resistência aos modos de vida da contemporaneidade. A questão central dessa discussão, como lembra Walsh (2005), é como incitar um (re)pensamento crítico, em termos de perspectiva, lógica e prática, que tenha como seu fundamento e razão de ser a transformação socioecômica, política e cultural da sociedade.

Nesse sentido, faz-se necessário desenvolver estudos que permitam criar bases de informações capazes de medir e avaliar o que é relevante para o desenvolvimento humano, com indicadores que sejam acessíveis à população e relevantes para as comunidades. Ou seja, desenvolver um pensamento crítico que não parta de perspectivas eurocêntricas baseadas na modernidade, mas que seja contruído na relação com as pessoas, incluindo os movimentos sociais, comunidades tradicionais/intencionais e universidades.

Aposta-se nesses movimentos como projetos de renovação dentro de uma ordem socioeconômica que tenha como base aquilo que é suficiente para a satisfação das necessidades, não somente dos seres humanos, mas também da natureza, abandonando o critério baseado na eficiência e no cálculo individual de custos e benefícios. Igualmente, espera-se que este ensaio teórico sirva como ponto de partida para futuras pesquisas relacionadas ao tema, com o objetivo de abrir debates e reflexões sobre o bem viver e outras abordagens de desenvolvimento, que, mesmo com diferentes propostas, podem permitir acertos, erros e reduções, estimulando a reflexão individual e coletiva de alternativas possíveis para construir um mundo mais sustentável.

\section{Referências}

Abbagnano, N. Dicionário de Filosofia. Tradução de Alfredo Bossi e Ivone Castilho Benedetti. 5. ed. São Paulo: Martins Fontes, 2007.

Acosta, A. El Buen Vivir en el camino del post-desarrollo: una lectura desde la Constitución de Montecristi. Friedrich Ebert Stiftung. Policy Paper: 9 octubre 2010.
Acosta, A. Buen Vivir Sumak Kawsay. Una oportunidad para imaginar nuevos mundos. Quito: Abya Yala, 2012.

Acosta A. O Bem Viver: uma oportunidade para imaginar outros mundos. Tradução de Tadeu Breda. São Paulo: Autonomia Literária/Elefante, 2016. 264 p.

Acosta, A.; Martínez, E.; Sacher, W. Salir del extractivismo: una condición para el Sumak Kawsay. Propuestas sobre petró- 
leo, minería y energía en Ecuador. En: Lang, M.; López, C.; Santillana, A. (Comps.). Alternativas al capitalismo del siglo XXI. Quito: Abya Yala, Fundación Rosa Luxemburgo, 2013.

Araújo, C. A. Bibliometria: evolução histórica e questões atuais. Em Questão, 12(1), 11-32, 2006.

Batista, M. K.; Grisci C. L. I.; Gallon, S.; Figueiredo, M. D. Slow movement: trabalho e experimentação do tempo na vida líquido-moderna. Psicologia \& Sociedade, 25(1), 2013.

Bauman, Z. Amor líquido: sobre a fragilidade dos laços humanos. Trad. de Carlos Alberto Medeiros. Rio de Janeiro: Jorge Zahar, 2004.

Brand, U.; Wissen, M. Crisis socioecológica y modo de vida imperial. Crisis y continuación de las relaciones sociedad-naturaleza en el capitalismo. En: Lang, M.; López, C.; Santillana, A. (Comps.) Alternativas al capitalismo del siglo XXI. Quito: Abya Yala, Fundación Rosa Luxemburgo, 2013.

Carrillo, A. T. Pasados hegemónicos, memorias colectivas e historias subalternas. En: Walsh, C. (Ed.). Estudios culturales latinoamericanos: retos desde y sobre la región andina. Quito: Abya-Yala, 2003.

Chalofsky, N.; Cavallaro, L. A good living versus a good life: meaning, purpose, and HRD. Advances in Developing Human Resources, 15(4), 331-340, 2013.

CEPAL (Comisión Económica para América Latina y el Caribe). Hacia un sistema de protección social más inclusivo en el Ecuador. Seguimiento y desenlace de un proceso de construcción de consensos en la búsqueda del Buen Vivir. César Carranza Barona, María Victoria Cisneros, (LC/L.3866), Serie Políticas Sociales, n. 205. Santiago de Chile. Publicación de las Naciones Unidas, 2014.

Coraggio, J. L.; Laville, J. L. Reinventar la izquierda en el siglo XXI: hacia un dialogo norte-sur. Coordinado por José Luis Coraggio y Jean-Louis Laville. 1. ed. Los Polvorines: Universidad Nacional de General Sarmiento, 2014. 548 p.

Coriolano, L. N. Os limites do desenvolvimento e do turismo: In: Coriolano, L. N. O turismo de inclusão e o desenvolvimento local. Fortaleza: FUNECE, 2003. p. 13-27.

Cortez, D. La construcción social del "Buen Vivir" (Sumak Kawsay) en Ecuador. Aportes Andinos, 28, 1-23, 2011.

Davis, A.; Wagner, J. R. Who Knows? On the importance of identifying "experts" when researching local ecological knowledge. Human Ecology, 31(3), 2003.
De La Cuadra, F. de. Buen Vivir: ¿Una auténtica alternativa post-capitalista? Polis, 14(40), 2015. Disponível em: $<$ http://www.scielo.cl/scielo.php?script=sci_arttext\&pi$\mathrm{d}=\mathrm{S} 0718-65682015000100001$ \&lang $=\mathrm{pt}>$

Estermann, J. 'Vivir bien' como utopía política: La concepción andina del "vivir bien" (suma qamaña/allin kawsay) y su aplicación en el socialismo democrático en Bolivia. Museo de Etnografía y Folclore (org.). En: Reunión Anual del Museo de Etnografia y Folclore: El Vivir Bien (2010). La Paz: 2011. Tomo II, 517-533.

FAO. Agricultura mundial: hacia los años 2015/2030. Informe resumido, 2006. Disponível em: <http://www. fao.org/docrep/004/y3557s/y3557s00.HTM $>$. Acesso em: maio 2016.

Fonseca, E. N. da (Org.). Bibliometria: teoria e prática. São Paulo: Cultrix, Ed. da USP, 1986.

Freire, P. Pedagogia do oprimido. São Paulo: Paz e Terra, 2012.

Garcia, E. Decrescimento e bem viver: algumas linhas de debate adequado. In: Léna, P.; Nascimento, E. P. do (Orgs.). Enfrentando os limites do crescimento: sustentabilidade, decrescimento e prosperidade. Rio de Janeiro: Garamond, 2012.

Georgescu-Roegen, N. The entropy law and the economic process. Cambridge (MA): Harvard University Press, 1971.

Gudynas E.; Acosta, A. El buen vivir mas allá del desarrollo. Quehacer, DESCO, 2008.

Gudynas, E. Buen Vivir: Today's tomorrow. Development, 54(4), 441-447, 2011.

Hidalgo-Capitán, A. L. El buen vivir ecuatoriano en el contexto de la economía política del desarrollo. En: Dominguez, R.; Tezanos, S. (Eds.). Actas del I Congreso Internacional de Estudios del Desarrollo. Santander: Universidad de Cantabria: 2012. Disponible en: $<$ http://congresoreedes.unican. es/actas/PDFs/202.pdf>. Acesso em: jan. 2017.

Hidalgo-Capitán, A. L. Seis debates abiertos sobre el sumak kawsay. Íconos. Revista de Ciencias Sociais, 48, 25-40, 2014.

Honoré, C. In Praise of Slow: How a Worldwide Movement Is Challenging the Cult of Speed. Carl Honoré Paperback - Import, 2005, October 1. 
Honoré, C. Devagar: como um movimento mundial está desafiando o culto da velocidade. Rio de Janeiro: Record, 2012.

Honoré, C. The slow fix: solve problems, work smarter, and live better in a world addicted to speed. New York: Harper One, 2013.

Houtart, F. El concepto de Sumak Kausay (Buen vivir) y su correspondencia con el bien común de la humanidade. Trabajo preparado en el marco del Instituto de Altos Estudios Nacionales (IAEN) para el Ministerio de Relaciones Exteriores del Ecuador, 2011. Disponível em: <http://67.192.84.248:8080/bitstream/10469/3523/1/ RFLACSO-ED84-04-Houtart.pdf $>$. Acesso em: jan. 2017.

Illich, I. Ouvres complètes. Paris: Fayard, 2004.

Kapp, K.W. Für eine ökosoziale ökonomie. Entwürfe und Ideen. Ausgewählte Aufsätze. Frankfurt: Fischer Taschenbuch Verlag, 1987.

Latouche, S. La Apuesta por el decrecimiento: ¿Cómo salir del imaginario dominante? Barcelona: Icaria, 2009.

Leff, E. Epistemologia ambiental. São Paulo: Cortez, 2001.

Leff, E. Racionalidad ambiental: la reapropiación social de la naturaleza. México: Siglo XXI, 2004.

Léon, I.; Senra, L. Aproximación a las situaciones de las campesinas y sus propuestas para conseguir la igualdad de derechos entre mujeres y hombres en el marco de la lucha por la Soberanía Alimentaria. Grupo de Mujeres Via Campesina. Estudio elaborado para Entrepueblos. Barcelona, 2009.

Mancebo, F.; Sachs, I. Transtions to sustainability. Dordrecht, Heidelberg, New York, London: Spring, 2015.

Mamani, F. H. Buen vivir / vivir bien. filosofía, políticas, estrategias y experiencias regionales andinas. Coordinadora Andina de Organizaciones Indígenas - CAOI. Lima: 2010.

Mardones, J. I. A.; Hernandez, C. de J. F.; Garcia, M. de J. G. La transdisciplinariedad una herramienta para apuntar al Buen Vivir. Polis, 14(40), 23-42, 2015.

Martins, J. C. O.; Coriolano, L. N.; Gurgel, L. I. Movimento slow e turismo comunitário: contraposições aos imperativos da pressa contemporânea. Caderno de Estudos e Pesquisas do Turismo, 3, 12-29, 2014.

Marx, K. Contribuição à crítica da economia política. Tradução e introdução de Florestan Fernandes. 2. ed. São Paulo: Expressão Popular, 2008.
Mayer, H. K. P. Slow cities: sustainable places in a fast world. Journal of Urban Affairs, 28(4), 321-334, 2006.

Max-Neef, M.; Elizalde, A.; Hopenhayn, M. Desarrollo a escala humana: una opción para el futuro. Development Dialogue, Número especial, CEPAUR. Fundação Dag Hammarskjold. Santiago, 1986.

Mignolo, W. Local/histories/global designs. Coloniality, subaltern knowledjes and border thinking. Princeton, N. J.: Princeton University Press, 2000.

Morin, E. Os sete saberes necessários à educação do futuro. Tradução de Catarina Eleonora F. da Silva e Jeanne Sawaya; revisão técnica de Edgard de Assis carvalho. 10. ed. São Paulo: Cortez; Brasília, DF: Unesco, 2005.

Nicolescu, B. Transdisciplinarity: past, present and future. In: Anais do $2^{\circ}$ Congresso Mundial de Transdisciplinaridade, Vila Velha/Vitória, 2005. Disponível em: <http://www. cetrans.com.br/artigos/Basarab_Nicolescu.pdf $>$. Acesso em: dez. 2016.

OCDE. The Bioeconomy to 2030: Designing a Policy Agenda: 2006. Disponível em: <http://www.oecd.org/dataoecd/ dataoecd $>$. Acesso em: out. 2016.

Pazos J. G.; Rojo P. P.; Sáenz M. E. Alternativas al modelo actual - Decrecimiento Buen Vivir: soberanía alimentaria, economía feminista, economía solidaria, soberania energética. Epalza, Bilbao: Sua Ediziok, 2014.

PNUD. Informe sobre Desarrollo Humano año 2004: La libertad cultural en el mundo diverso de hoy. Madrid: Mundi-Prensa Libros, 2004.

Quijano, A. Coloniality of power, eurocentrism, and Latin American, en Nepantla. Views from South, Durham, N. C.: Duke University, 1.3, 2000.

Radcliffe S. A. Desenvolvimento para uma era pós-neoliberal? Sumak kawsay, viver bem e os limites para a descolonização no Equador. Geoforum, 43(2), 240-249, 2012.

Sachs, I. Rumo à ecossocioeconomia: teoria e prática do desenvolvimento. São Paulo: Cortez, 2007.

Sampaio, C. A. C. (Org.). Gestão que privilegia uma outra economia: ecossocioeconomia das organizações. Blumenau, SC: Edifurb, 2010.

Sampaio, C. A. C. Cities and solution: urban ecosocioeconomics. Pullman, Washington: Washington State University, Fulbright Foundation. Report, 2015. 
Sampaio, C. A. C; Lesama, M. F.; Araújo, J. R.; Mendez, E. O. Perspectiva do turismo comunitário, solidário e sustentável. In: Sampaio, C. A. C.; Henríquez, C.; Mansur, C. (Orgs). Turismo comunitário, solidário e sustentável: da crítica às ideias e das ideias à prática. Blumenau: Edifurb, 2011. p. 23-30.

Sampaio, C. A. C.; Ceccato, M.; Mendonça, C.; Rehme, G. Slow city: como proposta de desenvolvimento territorial sustentável. Anais do II Seminário Internacional Culturas e Desenvolvimento, Chapecó, 2014.

Sassen, S. The Specialized Differences of Cities Matter in Today's Global Economy. 2008. Disponível em: <http:// www.saskiasassen.com/pdfs/publications/the-specialised-differences.pdf>. Acesso em: jan. 2017.

Sassen, S. Territorio, autoridad y derechos: de los ensamblajes medievales a los enssamblajes globales. Katz, 2010. $599 \mathrm{p}$.

Sen, A. Desarrollo y Libertad. Barcelona: Editorial Planeta, 2000 .

SENPLADES. Plan Nacional para el Buen Vivir 20092013: construindo un Estado plurinacional e intercultural. Quito-Equador: SENPLADES, 2009.

Singer, P. Economia solidária: um modo de produção e distribuição. In: Singer, P.; Souza, A. R. (Orgs.) A economia solidária no Brasil: a autogestão como resposta ao desemprego. São Paulo: Economia Contexto, 2000.

Teijlingen, K.; Hogenboom, B. Debating alternative development at the mining frontier: buen vivir and the conflict around el Mirador Mine in Ecuador. Journal of Developing Societies, 2017.
Thinley, L. J. Y. Values and Development: "Gross National Happiness" Values and Development: "Gross National Happiness". Text of the Keynote Speech Delivered at the Millennium Meeting for Asia and the Pacific, 30 October 01 November, Seoul, Republic of Korea: 1998.

Thomson, B. P. Perspectivas indígenas, buen vivir, kawsay Sumaq e decrescimento. Desenvolvimento, 54(4), 448-454, 2011.

Tortosa-Martínez, J.; Caus-Pertegaz, N.; Martínez-Román, M. A. Vida Triste y Buen Vivir según personas adultas mayores en Otavalo, Ecuador. Convergencia, 21(65), 2014.

Vanhulst, J. V.; Beling, A. E. Buen vivir: Emergent discourse within or beyond sustainable development? Ecological Economics, 101, 54-63, 2014.

Walsh, C. (Re)pensamiento crítico y (De)colonialidad. En: Walsh, C. (Ed.). Pensamiento crítico y matriz (de) colonial. Reflexiones latinoamericanas. Quito: Universidad Andina Simón Bolívar Ediciones Abya-Yala, 2005.

Walsh, C. Interculturalidad, colonialidad y educación. Revista Educación y Pedagogía, XIX(48), 2007.

Walsh, C. Interculturalidade, estado, sociedad. Luchas (de) coloniales de nuestra epoca. Quito: Universidad Andina Simón Bolívar e Abya-Yala, 2009.

Walsh, C. Desenvolvimento como Buen Vivir: acordos institucionais e (de) envolvimentos coloniais. Desenvolvimento, 53(1), 15-21, 2010.

Walsh. C. Pedagogías decoloniais: práticas insurgentes de resistir, (re)existir e (re)vivir. Tomo I. Série Pensamiento decolonial, 2012. 